\title{
China’s 2004 Economic Census and 2006 Benchmark Revision of GDP Statistics: More Questions Than Answers?
}

In 2006, China's National Bureau of Statistics undertook a benchmark revision of national income and product accounts statistics based on the findings of the 2004 economic census. The benchmark revision covers primarily the years 1993-2004 with revised economy-wide and sectoral output values. The new data have three implications. (i) Despite all the hype only a few years ago about data falsification by local statistical authorities in China, the 2004 economic census results validate the provincial aggregate output values and invalidate the center's national ones. (ii) At the national level, economy-wide as well as sectoral nominal values were revised but real growth rates of some sectors remained unchanged. That is not plausible, and implies that at least the secondary sector real growth rates are erroneous. (iii) The benchmark revision raises questions about the quality and meaning of a large body of official statistics. Ultimately, it casts doubt on the professionalism and sincerity of China's statistical authority.

JEL codes

C82 Methodology for Collecting, Estimating, and Organizing Macroeconomic Data

P27 Socialist Systems and Transitional Economies: Performance and Prospects

O4 Economic Growth and Aggregate Productivity

O53 Economywide Country-Studies Asia

Keywords (all: China): national income accounting, national income and product accounts, economic growth, growth estimates, benchmark revision, economic census, statistical breaks

\author{
Carsten A. Holz \\ Social Science Division \\ Hong Kong University of Science \& Technology \\ Clear Water Bay \\ Kowloon \\ Hong Kong \\ Tel/fax: +852 2719-8557 \\ socholz@ust.hk; http://ihome.ust.hk/ socholz
}




\section{Introduction}

Statistical data are rarely etched in stone. China's national income and product accounts statistics are no exception. The National Bureau of Statistics (NBS) revises most national income and product accounts data one year after they are first published. Following the 1993 tertiary (service) sector census, it conducted a benchmark revision of 1978-93 data; tertiary sector value added of 1993 was revised upward by 32 per cent, and thereby gross domestic product (GDP) by 10 per cent. A second benchmark revision occurred in early 2006, following the 2004 economic census of the secondary sector (industry, construction) and of the tertiary sector, with revisions primarily to the 1993-2004 data. Year 2004 GDP was revised upward by $16.8 \%$, making China, as of 2006, the world's fourth-largest economy. But these new data, in full published in the Statistical Yearbook 2006, come with a number of questions marks. ${ }^{1}$

\section{Are the provincial data better than the national ones?}

National GDP should equal the sum of provincial GDP (provincial gross value added). But prior to the 2006 benchmark revision, the sum of provincial GDP routinely exceeded national GDP. The discrepancy between the sum of provincial GDP and the NBS's national GDP figure increased continuously from 1996 through 2004. By 2004, the sum of provincial GDP was 19\% larger than the national value reported by the NBS (part B of Table 1). The national values are consistently lower than the sum provincial values in the secondary and tertiary sector.

The rising discrepancy coincided with a wave of reports on local data falsification in 1997 through approximately 2001. In response, the NBS, with support of the State Council and the Disciplinary Commission of the Chinese Communist Party Central Committee, in 1997/98 started a campaign against local data falsification. The continuing discrepancy between the national data and the sum provincial data all the way up through 2004 would suggest that the campaign against the "wind of falsification and embellishment" was not successful. ${ }^{2}$

In 2004, the then NBS commissioner, Li Deshui (李德水), offered a mix of technical reasons and corrections of exaggerated data as explanation of the discrepancy: provinces use 1990 base year prices when calculating real growth, while the NBS makes adjustments to this procedure based on a price index (and starting in 2004 the NBS fully switched to a price index); provinces double-count cross-provincial economic activities; provinces still use (presumably questionable) report forms for industrial enterprises with annual sales revenue below 5m yuan RMB; provinces use the opportunity of the as yet incomplete measurement of tertiary sector activities to adjust tertiary sector output upward such that the sectoral data add up to their desired aggregate output value; and provinces have incentives to exaggerate output (due to growth targets, comparisons of different localities by their output growth rates, and the use of statistics to measure local cadres' "achievements”).

\footnotetext{
$1 \quad$ The benchmark revision was announced by the NBS on 9 January 2006 with revised nominal values and real growth rates in the production approach to the calculation of GDP for 1993-2004. A follow-up notice on 8 March 2006 elaborated further. A four-volume compendium solely on the 2004 economic census (Economic Census 2004) became available in June 2006. The Statistical Abstract 2006 of May 2006 and then the Statistical Yearbook 2006 of September 2006 incorporated and extended the earlier announced revisions.

2 The issue of data falsification in the late 1990s is presented, among others, by Rawski (2001a, 2001b), and for national level data contested by Holz (2003).
} 
The benchmark revision national data suggest that the pre-economic census provincial GDP values were rather close on target, contrary to Li Deshui's arguments in favor of the original national values over the provincial ones. If the 2004 economic census results are correct, provinces under-reported tertiary sector value added (where Li Deshui claimed overreporting), had accurate data for the primary sector (agriculture), and over-reported in industry and especially in the small sector construction. (See part A of Table 1 for the relative size of sectors.) Overall, the sum of pre-economic census provincial GDP in 2004 was only 2.1\% larger than the revised national figure (part $\mathrm{C}$ of Table 1).

The pre-economic census national data, on the other hand, turned out to be rather inaccurate. The revised nominal GDP figure for 2004 is 16.8\% higher than the originally published one (part D of Table 1). Most of this increase is due to an almost 50\% upward revision to national tertiary sector value added. The annual revisions to primary sector value added across all years (1993-2004) remain below 1\% and those to industry below 4\%, while construction value added is reduced by up to $9.2 \%$.

Post-economic census provincial GDP values for 2004 and 2005 are available in the Statistical Yearbook 2006. In 2004, the sum of these provincial values is $4.8 \%$ higher than national post-economic census GDP. In 2005, the difference is $8.0 \%$, with almost no discrepancy in the primary sector, a $11.4 \%$ difference in the secondary sector, and a $6.7 \%$ difference in the tertiary sector (part E of Table 1). I.e., discrepancies between sum provincial and national data continue. ${ }^{3}$ The NBS has recently stated its intention to move to its own calculation of provincial GDP values, which would then presumably side-track data that come out of the provincial statistical bureaus altogether. ${ }^{4}$ But does the benchmark revision not perhaps suggest that the NBS should, at least for aggregate GDP, drop its own calculations and rely on the sum provincial data?

\section{Statistical break(s)}

The benchmark revision changed the nominal value added of all sectors in 1993-2004 (part D of Table 1), even though the primary sector was not part of the economic census. One potential explanation for the revision of primary sector nominal value added is the reclassification of economic activities among sectors due to the adoption of a new sectoral classification system. The classification "standard" (guobiao) GB/T4754-2002 (in the following abbreviated “GB2002”), issued in 2002, modifies the GB1994 (of 1994). ${ }^{5}$

The GB2002 incorporates a number of innovations in comparison to the GB1994. For example, in the GB2002 'logging and transport of timber and bamboo' and 'preliminary

\footnotetext{
3 Post-economic census revised time series values of provincial value added are available in the individual provincial statistical yearbooks of 2006. Data are available for all provinces since 1993 (and for some provinces also for some earlier years), except for Guizhou, for which the 2006 provincial statistical yearbook only presents value added data since 2000. Using the Guizhou data for 1993-99 published in Fifty-five Years, p. 881, and adding up provincial value added across provinces in each year, the resulting sum provincial value added shows only minute changes to the sum of the pre-economic census provincial data reported in the Statistical Yearbook of individual years (the data used in Table 1, part B).

See Xinbao (a Hong Kong daily newspaper), 22 May 06.

For a summary of the major changes see first through seventh 2003 issues of the NBS magazine Zhongguo tongji. The official GB classifications are not available and have to be gleaned from other sources, such as the population censuses with their data on laborers (as done in Holz, 2006c).
} 
processing of textile fibers' move from industry into agriculture. ${ }^{6}$ In the agricultural sector, 'household sideline business' is dissolved into the corresponding other (including industrial) sectors. The three main economic sectors thus are only approximately compatible between the GB1994 and the GB2002. ${ }^{7}$

A second potential explanation for the revision of primary sector nominal value added is that the GDP coverage in the economic census was expanded to newly include (i) economic activities previously ignored, such as those occurring in sub-ordinate units outside the main business of an enterprise, and (ii) economic activities captured through statistical compilations outside the economic census (and previously not included in GDP), such as home-owners renting out housing, home teaching, or childcare services (Xu Xianchun, 2006a, p. 17).

In which year do the 2006 benchmark revision data switch from the GB1994 to the GB2002 and to the expanded coverage (assuming that both switches occur at the same time) $?^{8}$ The economic census stipulation requires the economic census to collect data following the GB2002 (SC/NBS, 5 Sept. 2004). According to Xu Xianchun (许宪春, 2006a, p. 19), head of the National Income Accounts Division of the NBS, in revising pre-2004 values the NBS followed OECD advice and used the "trend-difference" method: the 1992-04 trend is established twice, using the pre-economic census (original) 2004 value as well as the post-economic census (new) 2004 value, and the annual relative divergence from the original trend is then applied to the new trend line to obtain annual post-economic census values for the years 1993-2003. ${ }^{9}$ This suggests that the NBS used the available 2004 nominal value added, following the GB2002 and with broader coverage, and simply linked it up with 1992 value added in order to revise the 1993-2004 values. The revisions to nominal primary sector value added are thereby explained. This appears the most plausible scenario.

It requires the assumption that the difference between the GB2002 and the earlier used classification in 1992 (and earlier), at the sectoral level, is zero, and that the value of economic activities previously not covered also was zero in 1992. Alternatively, a statistical

\footnotetext{
6 In the GB1994, the first is a sector within 'quarrying and mining', and the second a sector of the 'textile industry,' which in turn belongs to 'manufacturing.'

7 Beyond the new sectoral classification that applies to all variables, Xu Xianchun (2006a, pp. 17f.) elaborates on three innovations in the calculation of sectoral value added, implemented to better comply with international practices. Interest on household savings deposits was previously counted as financial sector value added, but is now attributed to the individual sectors that produced this particular value added. Depreciation on residential housing was previously based on construction costs, but is now based on current market values. Expenditures on computer software are not handled uniformly by all statistical units in China (the United Nations 1993 System of National Accounts regards it as gross fixed capital formation, the 1968 version, however, as an intermediate input); the economic census collected data on income from computer software sales which allows the NBS to systematically include approximate expenditures on computer software in gross fixed capital formation.

8 While economic activities could presumably be reclassified retrospectively, data on economic activities not captured in the past can probably not be collected retrospectively.

9 Qin Yao and Xue Jian (2006) report an identical procedure for the provincial-level Chongqing Municipality, with additional corrections and procedures for some variables. They refer to a NBS regulation no. 2 of 2006 entitled "niandu GDP lishi shuju xiuding fangfa" (Revision method for historical annual GDP data), a regulation that is not available in the laws and regulation database of China Infobank, nor on the NBS website or in standard law compendia.
} 
break occurs in 1992/93, which is then distributed across the years 1993-2004 via the trenddifference method. ${ }^{10}$

However, the national income accounts section of the Statistical Yearbook 2006 comes with a contrary note (p. 57, note b). The NBS, first, explicitly lists a number of reclassifications among sub-sectors of the tertiary sector that start in 2005 only; these de facto correspond to the GB1994 to GB2002 transition. ${ }^{11}$ Second, the NBS claims to include agricultural services with agriculture only since $2005 .^{12}$ The exclusion of agricultural services from agriculture violates both the GB1994 (as already previously known for the preeconomic census data) and the GB2002; it implies a statistical break in the primary and tertiary sector series between 2004 and 2005 (due to the switch of agricultural services). ${ }^{13}$ It also implies that we do not have any clue as to why the 2004 economic census, which excluded the primary sector, yielded new data on primary sector nominal value added for 1993-2004. One may further wonder if the revised pre-2005 data in general do not follow the GB2002, and the secondary sector therefore also is subject to a statistical break in 2004/05. ${ }^{14}$

\section{Spurious real growth rates}

The 2006 benchmark revision changed the real growth rates of tertiary sector value added and of GDP, but not those of the primary and secondary sectors. That is not plausible, and in one respect outright erroneous.

\section{Primary and secondary sector real growth rates 1993-2004}

The post-economic census adjustments to primary sector nominal value added increased the previously published value of 1993 by only $0.1 \%$, but that of 2004 by $0.9 \%$ (with a continuous increase in the years in between, see part $\mathrm{D}$ of Table 1). I.e., the value of newly added agricultural activities between 1993 and 2004 increases significantly faster than the value of original agricultural activities, and if the newly added activities were subject to a similar deflator as the original ones, the resulting new real growth rate of total agricultural

10 It might be of such small size might as to not be noticeable at the level of accuracy at which the NBS reports data.

11 The GB2002 introduced reclassifications across sectors, of which some where noted above, but also numerous reclassifications within sectors (at the sub-sectoral level). Thus, within the tertiary sector, the firstlevel classification is revised and expanded considerably, with numerous reclassifications of lower-level sectors. Within industry, the main changes are reallocations of third-level sectors between industrial second-level sectors. In construction, one significant change is the switch of institutions involved in preparatory work for construction from the construction sector to the tertiary sector (into polytechnic services).

12 In 2003, the most recent year for which the data are available (pre-economic census values), value added in agricultural services was equivalent to $1.85 \%$ of primary sector value added (Statistical Yearbook 2005, pp. 51, 55).

13 The GB1994 presumably already included agricultural services in agriculture, but the national income and product accounts statistics continued to include agricultural services in the tertiary sector. Two manuals on national income accounting of 1997 and 2001 both list agricultural services as outside the primary sector (NBS, 1997; NBS, 2001). As to the GB1994 already including agricultural services in agriculture, see Holz (2006c).

Zhongguo tongji, no. 3 (2003), pp. 10f. outlines the changes in the primary sector between the GB1994 and the GB2002; it does not mention any reclassification of agricultural services.

14 The official explanation of how 1993-2003 data were revised now also needs to be augmented by a statement that for the purpose of revising 1993-2003 data, the same classification was applied to the posteconomic census year 2004 data as was in use for the 1992 data. 
activities should go up. What the NBS has done, instead, by not changing the real growth rates, is to impose an upward revision on the implicit deflator. (The NBS publishes nominal values and real growth rates; these together imply a particular deflator.) One could believe a constant real growth rate series if the 1993 nominal primary sector value had been revised by the same percentage as the 2004 primary sector value, but that is not what the statistics show. ${ }^{15}$

Compared to the primary sector, the revisions to 2004 value added in the secondary sector are much larger ( $+3.8 \%$ for industry, $-9.2 \%$ for construction). But the pattern of change over time is similar to the primary sector in that the revisions to the 1993 values are also significantly smaller $(+0.3 \%,-0.8 \%)$ than those to the 2004 values. I.e., the two secondary sector sub-sectors have experienced changes in nominal output that differ significantly from the pattern inherent in the previously published data, and one would expect the real growth rates to change correspondingly, but those have remained unchanged. The implication of not changing real growth rates is that the NBS raised the implicit deflator of industry, and lowered that of construction.

There are two possible interpretations of this pattern. One, the NBS used the opportunity of the 2006 benchmark revision to in agriculture, industry, and construction switch to a new deflator. The census was about year 2004 nominal secondary and tertiary sector data, in particular output data, and not about the collection of comprehensive price data for 19932004 across all three sectors. The new deflators, thus, would have to come from some other source. But where should such new deflators come from? Why should they cover only the period 1993-2004 and not 1978-92?? ${ }^{16}$ And why should they be of exactly that size which keeps the real growth rates of all years unchanged and thus causes a 1:1 change in nominal values, when the economic census was about collecting new nominal output data for industry and construction (and the tertiary sector), and new data was, according to Xu Xianchun of the NBS, indeed collected? ${ }^{17}$ This scenario is not plausible.

A second possible interpretation is that the implicit deflators are not changed. Then either the revised 1993-2004 nominal values or the unchanged real growth rates (or both) must be incorrect. To take the case of industry, the 2004 economic census resulted in an increase of 2004 nominal value added of industry by 3.8\%, and no change in the 1992 value.

Suppose that all of the 2004 adjustment were due to reclassifications among sectors. Then the reduction in reclassifications to zero in 1992 is not plausible. More likely than not, the reclassification should occur in roughly the same proportion in each year. Reducing the revisions to zero in 1992 would simply be a matter of convenience, in order to not have to revise pre-1993 data. The implication would be that the pre-2004 nominal values are all

15 On the other hand, it may also be the case that the annual changes in real growth rates are too small to be captured by an official (percentage) real growth rate reported only with one decimal.

16 The years 1978-93 were subject to the previous benchmark revision following the 1993 tertiary sector census; that census largely retained the earlier published implicit deflators. Of the two sub-sectors of the tertiary sector on which data were published in the Statistical Yearbook prior to and after the tertiary sector census, the first, transport \& telecommunications, did not experience any change in deflator in the years 1979-89, and the second, commerce \& catering, did not experience any change in deflator in 1979 and 1980, a two percentage point change in 1981, and very minor changes, typically at the first percentage decimal, in 1982-1992. The primary and secondary sector (and secondary sector sub-sectors) did not experience any change in deflator. (Statistical Yearbook 1993, pp. 31f., 1994, p. 32, 1995, p. 32, and 2005, pp. 51 and 54.)

17 See Xu Xianchun (2006b), p. 8, where he reports that "the economic census led to the discovery that the previous data sources were missing a lot so that many economic activities were left out.” 
underestimates, i.e., should have experienced larger reclassifications. But with the collection of new data, not all of the 2004 adjustment can be due to reclassifications. In that case the retention of the original real growth rates in the revised dataset does not make sense. The official statements on the use of the "trend-difference" method (for nominal value added) suggest that the NBS simply adjusted pre-2004 nominal values and ignored the need to adjust real growth rates.

\section{Inconsistent calculation of secondary sector real growth rates 1993-2004}

The fact that the NBS retained the pre-economic census secondary sector real growth rates implies an inconsistency. The secondary sector real growth rate is a weighted average of the real growth rates of industry and construction, with as weights the shares of industry and construction in secondary sector nominal value added. Retaining the pre-economic census secondary sector real growth rates implies that the NBS did not change the weights of industry and construction in the calculation of secondary sector real growth rates. This is despite the increase in nominal value added of industry and the decrease in nominal value added of construction, and even though these changes are sufficiently large to at least in some years change the real growth rate of the secondary sector, calculated with one decimal and using a Törnqvist index or previous-year weights. This appears an outright mistake.

It is not an outright mistake only if the NBS uses pre-1993 nominal weights to aggregate sectoral real growth rates. However, that would amount to gross misspecification because inappropriate weights would be applied to sectoral growth rates. It would also mark a severe deviation from earlier practice in that the official pre-economic census GDP real growth rates are best matched by applying previous-year weights to sectoral real growth rates or by using a Törnqvist index. ${ }^{18}$

\section{Tertiary sector real growth rates 1978-2004}

In the tertiary sector, economic census results led to upward revisions to both the nominal values and the real growth rates of 1993-2004. There is, thus, no issue of unrevised real growth rates. $^{19}$

The revisions to tertiary sector data extended further, to the nominal values of 19781992. ${ }^{20}$ The corresponding real growth rates remained unchanged, implying changes to the implicit tertiary sector value added deflator of these years. (Nominal GDP was revised

\footnotetext{
18 Using decennial weights (1990, 2000), on the other hand, yields results that are rather different from the official pre-economic census GDP real growth rates. None of the weights tested yields a perfect match to the official real GDP growth rates (pre-economic census, or post-economic census). Therefore, a compelling check of if the NBS switched to post-economic census weights in calculating (post-economic census) GDP values is not possible. The data reveal that the NBS changed the weights between the pre-economic and post-economic census real GDP growth rates; for the post-economic census real GDP growth rates, the post-economic census weights yield a better match than the pre-economic census weights (using a Törnqvist index). For the secondary sector, however, it is logically necessary that if industry and construction real growth rates do not change while the weights change to the extent as they do, the secondary sector real growth rate must change (at the reported level of data accuracy).

19 The implicit deflator of all years was also revised upward.

20 This is a measure potentially unrelated to the 2004 economic census. It was not mentioned in any of the announcements on the 2004 economic census.
} 
accordingly.) The NBS offers no explanations for the revision of tertiary sector nominal value added of 1978-1992. Three conjectures are the following. First, these revisions may reflect an expansion of the coverage of economic activities. But then why is the new coverage only applied to the tertiary sector?

Second, the revisions to 1978-92 tertiary nominal tertiary sector value added could be due to the new application of the GB2002. The national income and product accounts data would then potentially experience a statistical break between the GB1994 and the GB2002 in the tertiary sector in 1978 (onwards), and in the primary and secondary sector in 1993 (onwards). This would further imply that the revised 1978-92 sectoral values are potentially internally inconsistent, due to double-counting and/or omission of economic activities that were reclassified between the GB1994 and the GB2002. But an inconsistent treatment of sectors is little plausible. Furthermore, the above mentioned note in the Statistical Yearbook 2006 suggests that the statistical break due to reclassifications occurs in 2002.

Third, the pre-economic census data may have contained a mistake. The preface to the compendium GDP 1952-95 with long-run GDP data, nationally and by province, for 1952-95, states that the national and provincial data reflect the benchmark revisions that followed the tertiary sector census of 1993, except for the case of Guangdong. The phrasing is ambiguous as to if the Guangdong exception also affects the national data; presumably it does, because why should the national data be based on revised national—including Guangdong — data but the Guangdong provincial data not? (This would only be plausible if the national data were compiled independently of the provincial data, which seems unlikely in the case of the tertiary sector census.)

Suppose the national data in GDP 1952-95 (p. 27) were indeed based on the pre-tertiary sector census Guangdong tertiary sector values. With identical values for 1978-92 tertiary sector value added in the most authoritative source, the Statistical Yearbook (issue of 2005, p. 51), all published pre-economic census national values would then be based on Guangdong values that do not incorporate the 1993 tertiary sector census. The Statistical Yearbook 2006 (p. 51) raises tertiary sector value added of 1992 by 28.54b yuan RMB. This amount is equal to $36.87 \%$ of the published Guangdong (original) 1992 tertiary sector value added of $77.41 \mathrm{~b}$ yuan RMB (GDP 1952-95, p. 724), the value that does not incorporate the 1993 tertiary sector census revisions. This percentage is remarkably close to the average national upward adjustment of 1992 tertiary sector value added by 33.15\% (Statistical Yearbook 1994, p. 32, 2005, p. 51). ${ }^{21}$

Because the proportion of the change to tertiary sector value added is rather similar in 1978 and 1992, with 2.5\% and 3.1\% upward revisions, keeping the old real growth rates appears a simplifying assumption with limited consequences. ${ }^{22}$

21 The post-economic census revised Guangdong tertiary sector value added of 1992, in the provincial Guangdong Statistical Yearbook 2006, p 91, is 88.139b yuan RMB, reflecting an upward revision of only $10.73 \mathrm{~b}$ yuan RMB (rather than of 28.54b yuan RMB). This detracts from the Guangdong explanation.

22 Between 1978 and 1992, the (cumulative) implicit deflator of tertiary sector value added using the preeconomic census nominal values rose $28.5 \%$, and the implicit deflator using the post-economic census nominal values $29.9 \%$. No systematic difference persists across all individual years. The two implicit deflators differ significantly in 1978, the connecting year. In 1978, the original pre-economic census implicit deflator (from the Statistical Yearbook 2005) is $0.8 \%$ and the post-economic census implicit deflator 3.3\%. 
In the years 1993-2004, with only the tertiary sector real growth rates allowed to increase, the overall effect on real GDP growth is smaller than the increase in nominal 2004 GDP of $16.8 \%$ over the original figure would suggest. The original average annual real growth rate (Statistical Yearbook 2005, p. 54) between 1992 and 2004 is 9.4\% and the revised one (Statistical Yearbook 2006, p. 60) is $9.9 \% .^{23}$ (See Table 2 for the annual real growth rates.) However, a "mixed" real growth rate that combines the revised nominal data with the deflators implicit in the pre-economic census data, using a Törnqvist index of real GDP growth, is $10.7 \% .{ }^{24}$ (The calculation assumes that the sectoral reclassifications do not change the appropriateness of the earlier implicit sectoral deflators.) In other words, the official posteconomic census real GDP growth rate was revised upward by 0.5 percentage points per year, but should in all likelihood have been revised upward by 1.3 percentage points. ${ }^{25}$

Going one step further and applying the first published implicit sectoral deflators (agriculture, industry, construction, tertiary sector) to the revised nominal sectoral values (following the 2004 economic census), and aggregating into real GDP growth using the Törnqvist index, results in an average annual real growth rate for $1992-2004$ of $10.9 \%{ }^{26}$ This again assumes that the earlier implicit sectoral deflators are appropriate for the new classification. Beyond reclassifications at the level of the main economic sectors, this also ignores that the first published tertiary sector deflator may no longer be accurate due to changes in the relative nominal size of tertiary sector sub-sectors in the benchmark revision. Compared to the real growth rates as first published, the combination of 2004 economic census nominal values and the first published implicit deflator yields real growth rates that in 1993 and 1994 are several percentage points higher (the 1993 difference represents in part the

23 Wu (2006), in a paper that I came across after submission of this article, examines in greater detail the official retrospective adjustment method to nominal value added (and GDP); he is particularly interested in the fact that the 1998 real GDP growth rate is the only one that has not been adjusted (Table 2).

24 The latter real GDP growth rate (of 10.7\%) is the weighted average (Törnqvist index) of the real growth rates of primary, secondary, and tertiary sector, where the secondary sector real growth rate itself is the weighted average of the real growth rates of industry and construction. Weights are based on revised (following the 2004 economic census) nominal sectoral value added. Real growth rates of individual sectors are obtained using the revised nominal values combined with the deflators implicit in the Statistical Yearbook 2005 data. 25 The upward revision contrasts sharply with Maddison's (1998) downward revisions to China's reform period real growth rates. (Holz, 2006a, argued that Maddison's revisions are not justified, followed by further discussion in Maddison, 2006, and Holz, 2006b.) The 2006 benchmark revision to 1993-2004 nominal values using the trend-difference method makes one wonder about the possibility that 1978-93 nominal values ought to be raised (then using a different method of revision), as the World Bank, with work by Albert Keidel, once suggested in the early 1990s but then abandoned (discussed by Holz, 2002). That, in turn, might affect real growth rates (downward).

${ }_{26}$ The NBS in the Statistical Yearbook for each year first offers the preliminary nominal data with a real growth rate for the latest year, and in the next issue provides the final (revised) nominal data for that particular year but usually does not revise the originally published real growth rate. I.e., in the annual revisions embedded in the Statistical Yearbook series, the NBS already once implicitly revised the sectoral deflators of all years except of the most recent year. Annual revisions to the deflators are not plausible because the data that underlie the deflators are available when the nominal data are first published, and are not subject to later revisions. In detail, the procedure here is: (i) the nominal revised (2004 economic census) value added data of the primary sector, industry, construction, and the tertiary sector of all years 1993-2004 are deflated using the first published implicit deflators of these sectors (as calculated from first published nominal and real growth data in the Statistical Yearbook series); (ii) the real growth rates of industry and construction are aggregated into secondary sector real growth rates using the Törnqvist index with post-economic census nominal value added weights for industry and construction; (iii) the real growth rates of the primary sector, secondary sector, and tertiary sector are aggregated into real GDP growth rates again using the Törnqvist index with post-economic census nominal value added weights of these three sectors. (The corresponding annual series are not included in Table 2.) 
benchmark revision following the 1992/93 tertiary sector census), and in the years since are higher by between a fraction of a percentage point and up to two percentage points, except in 1996, with a 0.2 percentage point decline.

\section{Creating havoc across a wide range of statistical data}

In the expenditure approach to the calculation of GDP, which is not the official approach to calculating GDP in China, the NBS chose to revise all nominal values back to 1978. In comparison to the (official) production approach value of GDP (discussed above), the revised expenditure approach value is now 1.1\% lower in 1978, and 2.4 and 2.3\% higher in 1992 and 2004. In the expenditure approach, real growth rates (and thus implicit deflators) are not available except for per capita household consumption.

Table 3 reports the revisions to nominal data. Expenditure approach GDP in 2004 was revised upward by $12.6 \%$. This comprises, first, a $15.4 \%$ upward revision to final consumption, which in turn reflects an $8.2 \%$ upward revision to household consumption and a 41.1\% upward revision to government consumption. Within household consumption, rural consumption was revised downward by $26.6 \%$ and urban consumption upward by $31.9 \%$. Second, gross capital formation was revised upward by $10.0 \%$, which in turn reflects a $4.4 \%$ upward revision to gross fixed capital formation and a 673.2\% upward revision to inventory investment.

The accuracy of the expenditure approach has been questioned before: calculating expenditure approach household consumption in accordance with the NBS explanations on how the NBS does it, one is unable to replicate the NBS's results (Holz, 2004a). The 2006 benchmark revision confirms the earlier suspicions. ${ }^{27}$ The opposing revisions to rural vs. urban nominal consumption reflect (i) a redefinition of who is "rural” vs. "urban" as well as (ii) changes to the real growth rates. Figure 1 shows how the (unchanged) total population is newly split into rural vs. urban for all years since 1978, with the relabeling of a large share of the "rural" as "urban" population in the most recent years; the urban citizen consumes more than the rural one, and thus average consumption increases. ${ }^{28}$ Per capita real growth rates were revised slightly in all years (1978-2004), rising from an average annual 7.03\% to 7.35\% for the total population, falling from $6.24 \%$ to $5.71 \%$ for the rural population, and falling from $6.28 \%$ to 6.18 for the urban population. ${ }^{29}$ The implicit deflators are unchanged.

\footnotetext{
27 The household consumption measure relies largely, but not solely, on social retail sales (see Holz, 2004a). Retail sales focus on purchases by households and other social entities in retail transactions, something that is difficult to measure. The NBS is reportedly “gradually” (zhubu 逐步) switching to the sales of commercial units as the variable on which to collect data. Since 2003, it reportedly dropped the direct retail sales of consumer goods by factories from the "social retail sales.” In addition, or as consequence, the two categories "manufacturing” and "agricultural production" within the social retail sales measure were dropped. (Zhongguo tongji, no. 1, 2003, p. 15)

28 The newly adopted rural-urban population data implicit in the aggregate and per capita household consumption data closely match the rural-urban population data published in the Statistical Yearbook series. Holz (2004a) discusses the two sets of population data-those used by the NBS in deriving the (earlier) household consumption data and those in the Statistical Yearbook-and points out the rise in consumption values that would follow from adopting the latter (as now done by the NBS, in the 2006 benchmark revision). 29 For the rural (urban) population, the difference in pre- and post-economic census real growth rates is not uniformly of the same sign in all years. (Data sources for the real growth rates are the same as listed with Figure 1 for per capita values.)
} 
The revisions to government consumption are very large and one may wonder where the 41.1\% upward revision could possibly come from. Does the government have many more people on its payroll than it officially admits, or did it spend many times more on the military than originally thought? ${ }^{30}$

The seven-fold upward revision to inventory investment suggests that this item is a rather meaningless residual in the NBS's calculations. ${ }^{31}$ This implies, for example, that the data on inventory change cannot serve as a measure of macroeconomic cycles. ${ }^{32}$

A third approach to the calculation of GDP, beyond the production and the expenditure approaches, is the income approach where GDP equals labor remuneration, net taxes on production, depreciation, and the operating surplus. These data have always been published at the provincial level only, and only in nominal form. Retrospectively revised income approach data are not available.

From 1978 through 2003 (no data are available for 2004), the shares of each of the four components in income approach GDP are approximately constant. But, as Figure 2 shows, in 2005 the share of labor remuneration drops from its 2003 level of 0.50 to 0.41 (the absolute, nominal value increases), and the share of operating surplus jumps from 0.20 to 0.30 . In other words, the NBS has previously overestimated labor remuneration by $25 \%$ and underestimated operating surplus by $50 \%$. Because the official value added data for the tertiary sector are mostly derived from income data, the revisions to the income approach data have to square with the upward revision to tertiary sector value added in the production approach; ${ }^{33}$ given that the tertiary sector is relatively labor-intensive, one would expect an increase in tertiary sector value added to go hand in hand with an increase in the economy-wide share of labor remuneration in GDP, rather than with the decrease documented in Figure 2.

30 Government consumption comprises the four items (i) routine (jingchangxing 经常性) expenditures of administrative facilities (shiye danwei 事业单位) paid for out of the budget, (ii) routine expenditures paid for out of extrabudgetary funds, (iii) fixed asset depreciation of administrative units (xingzheng danwei 行政单位) and of not-for-profit administrative facilities, and (iv) gross output value less business revenue of urban and rural neighborhood committees. For details on the numerous subcategories of each of these three items see NBS (1997), pp. 153-6; the first item, for example, includes military expenditures.

31 At the provincial level, on the other hand, net exports are likely to be obtained as residuals. That in turn requires inventory investment to be estimated rather than being obtained as residual. The sum provincial inventory investment may therefore be a somewhat reliable measure for use in business cycle analysis. In recent years, the (pre-economic census) sum provincial value was many times the national value of inventory investment (in 2004, fourteen times).

32 The $4.4 \%$ upward revision to 2004 gross fixed capital formation appears relatively small, but because gross fixed capital formation accounts for $41 \%$ of total expenditure approach GDP, it is a large absolute amount. Without any explanation by the NBS of where the increase comes from, it is not clear if (i) this is a statistical break per se, in terms of a redefinition of the term "gross fixed capital formation", (ii) constitutes an admission by the NBS that its investment statistics, from which gross fixed capital formation values are derived, have been inaccurate in the past, or (iii) is simply a convenient adjustment for expenditure approach GDP to come close to the post-economic census production approach GDP value. Presumably, part of the $4.4 \%$ increase consists of expenditures on computer software that are now supposedly consistently counted as gross fixed capital formation (Xu Xianchun, 2006a, p. 18).

33 Because the income approach data are provincial data, part $\mathrm{C}$ of Table 1 provides the relevant comparison. It shows that pre-economic census sum provincial tertiary sector value added falls $8 \%$ short of post-economic census national tertiary sector value added. On the use of the income approach in the calculation of value added in several tertiary sector sub-sectors see Table 3 in Holz (2004b). 


\section{Conclusions}

The fact that the 2004 economic census validates original provincial GDP data and invalidates original national GDP data raises questions about the capacity of China's national statistical authority to accurately compile national data. The 2006 benchmark revision to 1993-2004 primary sector value added is either a mystery or the explanations in the Statistical Yearbook 2006 on the coverage of the official data are wrong. All sectoral value added series of 1993-2004 experience a statistical break either in 1992/93 (distributed across the following years) or all at once in 2004/05 (if the explanations in the Statistical Yearbook 2006 were correct). Primary and secondary sector real growth rates of 1993-2004 should have been revised but were not; those of the secondary sector are now logically wrong. The official revised average annual real GDP growth rate of 1993-2004 may be 0.8 percentage points too low.

The 2006 benchmark revision opens a window on how the NBS operates. First, the NBS is either incapable or unwilling to properly explain how the 2006 benchmark revisions were conducted, where the statistical breaks are, when they occur, and of what size they are. Second, in recent years the NBS has repeatedly dropped hints of under-reported national tertiary sector value added, which suggests it knowingly reported false GDP data for at least the most recent years. Third, by not revising secondary sector real growth rates, the NBS shows itself incapable of adding up two plus two. It appears as if the NBS simply did not want to increase the real growth rates in these two sectors. ${ }^{34}$ At that point, the NBS reveals itself as, at best, a political propaganda organ-don't revise GDP growth rates up too muchwith scarce, or no regard for the compilation of accurate statistics. "Cooking the data" substitutes for logical mathematical operations.

The size of some of the revisions to expenditure approach data and of the innovations in the case of the income approach data appear very much out of proportion. If the statistics published by NBS are that much off, where the national income and product accounts are at the core of China's statistical data, then what does that mean for related and, perhaps even worse, for unrelated and less "important" statistics? Is every one of the thousand pages of the Statistical Yearbook taking us for a ride?

With a solid basis in form of the 2004 economic census, one would expect future data to be more reliable. But reports from the grassroots suggest that the economic census was, at least in some localities, poorly organized, possibly severely under-funded, and in several respects not suited to capture the value of economic activities. ${ }^{35}$ If the economic census were indeed a complete waste of time and money (unlikely), then the possibility arises that the NBS had good reason to retain its earlier real growth rates in the primary and secondary sector. But that still means that the NBS works with sectoral (and GDP) real growth rates that are inconsistent, fudges statistical breaks, and moves mountains in the expenditure and income approaches. In the end, one may wonder if the functionaries of political systems such

\footnotetext{
34 Xu Xianchun (2006a, p. 17) perhaps hints at the reason for avoiding revisions. He explains that the new treatment of financial sector value added has been on the agenda for a long time, but the resulting large change in the value of financial sector value added would have created a statistical break which would have been "not easy for the relevant departments and society to accept," while retrospective revisions of earlier data require a suitable opportunity, "otherwise everybody disapproves."

35 See, in particular, Xie Haiqiu and Zhang Lihua (2006), who suggest that in their locality, Hunan Province Zhuzhou Municipality (株洲), GDP may well be 8\% higher than the economic census suggests. Liu Xiaoyue (2006) reports on problems in data collection at the lower-level tiers in general, including in censuses.
} 
as that of China can ever play by the rules of professionalism and honesty. For the time being, the 2006 benchmark revision implies that Chinese statistics have to be taken with a rock of salt. 


\section{References}

Economic Census 2004. Zhongguo jingji pucha nianjian-2004 (China Economic Census Yearbook-2004). Four volumes. Beijing: Zhongguo tongji chubanshe, (May) 2006.

Economic Census 2004 (9 Jan. 2006). "Guanyu wo guo guonei shengchan zongzhi lishi shuju xiuding jieguo de gonggao" (Announcement of the results of the historic revisions of China’s GDP data). http://www.stats.gov.cn/tjdt/zygg/t20060109_402300176.htm (accessed on 27 April 2006).

Economic Census 2004 (8 March 2006). "Jingji pucha hou zhongguo GDP shuju jiedu zhi yi: GDP zongliang, zengzhang sudu ji renjun GDP” (China's GDP figures after the economic census, part 1: GDP volume, GDP increase, and per capita GDP), http://www.stats.gov.cn/zgjjpc/cgfb/ (accessed on 27 April 2006).

Fifty-five Years. Xin zhongguo wushiwu nian tongji ziliao huibian 1949-2004 (Compendium of statistical data on fifty-five years of new China 1949-2004). Beijing: Zhongguo tongji chubanshe, 2005.

GDP 1952-95. Zhongguo guonei shengchan zongzhi hesuan lishi ziliao 1952-1995 (Historical data on China's gross domestic product 1952-1995). Dalian: Dongbei caijing daxue chubanshe, 1997.

Holz, Carsten A. "Institutional Constraints on the Quality of Statistics in a Developing and Transitional Economy: the Case of China.” China Information 16, no. 1 (2002): 25-67. . "'Fast, Clear and Accurate:' How Reliable Are Chinese Output and Economic Growth Statistics.” China Quarterly, no. 173 (March 2003): 122-63. . “Deconstructing China’s GDP Statistics.” China Economic Review 15, no. 2 (2004a): 164-202. . "China’s Statistical System in Transition: Challenges, Data Problems, and Institutional Innovations.” Review of Income and Wealth 50, no. 3 (Sept. 2004b): 381-409. . "China's Reform Period Economic Growth: How Reliable Are Angus Maddison's Estimates?” Review of Income and Wealth 52, no. 1 (March 2006a): 85-119. . "China's Reform Period Economic Growth: How Reliable Are Angus Maddison's Estimates? Response to Angus Maddison's Reply.” Review of Income and Wealth 52, no. 3 (Sept. 2006b): 471-5. . "Measuring Chinese Productivity Growth, 1952-2005.” 22 July 2006c. Mimeo, Hong Kong University of Science \& Technology, available at http://ihome.ust.hk/socholz.

Li Deshui. "Guanyu GDP de ji dian sikao" (Some considerations on GDP). Jingji yanjiu, no. 4 (2004): 26-8.

Liu Xiaoyue. "Paiyou jienan zhong zai jiceng: baixian diaoyan hainanzu you gan er fa” (The key to solving the worries lies at the grassroots: reflections of the Hainan group of the hundred-county-survey campaign). Zhongguo tongji, no. 8 (Aug. 2006): 10-12.

Maddison, Angus. Chinese Economic Performance in the Long Run. Paris: Development Centre of the Organisation for Economic Co-operation and Development, 1998. . "Do Official Statistics Exaggerate China's GDP Growth? A Reply to Carsten Holz." Review of Income and Wealth 52, no. 1 (March 2006): 121-6.

NBS (National Bureau of Statistics). Zhongguo niandu guonei shengchan zongzhi jisuan fangfa (Methods of calculation for China's annual GDP). NBS National Accounts Division. Beijing: Zhongguo tongji chubanshe, 1997. . Zhongguo guonei shengchan zongzhi hesuan shouce (Manual on the compilation of China's GDP). 2001.

Qin Yao, and Xue Jian. “Chongqing hesuan lishi shuju tiaozheng fangfa chutan” (Preliminary exploration of Chongqing's adjustment method in calculating historical data). Zhongguo tongji, no. 9 (Sept. 2006): 6-8. 
Rawski, Thomas G. "China by the Numbers: How Reform Has Affected China's Economic Statistics.” China Perspectives, no. 33 (Jan./Feb. 2001a): 25-34. . "What Is Happening to China’s GDP Statistics." China Economic Review 12, no. 4 (2001b): 347-54.

SC (State Council) and NBS. 5 Sept. 2004. “Quanguo jingji pucha tiaoli” (National economic census stipulation). In the rules and regulation database of China Infobank (http://www.chinainfobank.com).

Statistical Abstract 2006. Zhongguo tongji zhaiyao 2006 (China Statistical Abstract 2006). Beijing: Zhongguo tongji chubanshe, 2006.

Statistical Yearbook. Zhongguo tongji nianjian (China Statistical Yearbook). Beijing: Zhongguo tongji chubanshe, various years.

Wu, Harry X. "The Chinese GDP Growth Rate Puzzle: How Fast Has the Chinese Economy Grown.” Paper Prepared for the $29^{\text {th }}$ General Conference of the International Association for Research in Income and Wealth, Joensuu, Finland, August 20-26, 2006. The Hong Kong Polytechnic University, undated. Downloaded 1 Sept. 2006 from website that is no longer available. Apparently identical version, dated July 2006, available at http://histat.ier.hit-u.ac.jp/research/discussion/2006/pdf/D06-176.pdf, accessed 20 February 2007.

Xie Haiqiu and Zhang Lihua. "Dui shouci jingji pucha ruogan wenti de sikao yu jianyi” (Thoughts and suggestions regarding some problems in the first economic census). Tongji jiaoyu, no. 2 (2006): 11-3.

$\mathrm{Xu}$, Xianchun. "Guanyu jingji pucha niandu GDP hesuan de bianhua” (Changes in the calculation of annual GDP in the economic census). Jingji yanjiu, no. 2 (Feb. 2006a): 1620.

. "Dui woguo jidu guonei shengchan zongzhi hesuan de sikao" (Thoughts on the calculation of quarterly GDP in China). Zhongguo tongji, no. 6 (June 2006b): 8f. 
Table 1. Pre- Vs. Post-Economic Census Nominal Value Added

\begin{tabular}{|c|c|c|c|c|c|c|}
\hline & GDP & $\begin{array}{c}\text { Primary } \\
\text { sector }\end{array}$ & $\begin{array}{l}\text { Secondary } \\
\text { sector }\end{array}$ & $\begin{array}{c}\# \\
\text { Industry }\end{array}$ & $\begin{array}{c}\# \\
\text { Construction } \\
\end{array}$ & $\begin{array}{c}\text { Tertiary } \\
\text { sector }\end{array}$ \\
\hline \multicolumn{7}{|c|}{ A. Nominal values (b yuan RMB), post-economic census } \\
\hline 1978 & 3645.2 & 1018.4 & 1745.2 & 1607.0 & 138.2 & 881.6 \\
\hline 1979 & 4062.6 & 1258.9 & 1913.5 & 1769.7 & 143.8 & 890.2 \\
\hline 1980 & 4545.6 & 1359.4 & 2192.0 & 1996.5 & 195.5 & 994.2 \\
\hline 1981 & 4891.6 & 1545.6 & 2255.5 & 2048.4 & 207.1 & 1090.5 \\
\hline 1982 & 5323.4 & 1761.6 & 2383.0 & 2162.3 & 220.7 & 1178.8 \\
\hline 1983 & 5962.7 & 1960.8 & 2646.2 & 2375.6 & 270.6 & 1355.7 \\
\hline 1984 & 7208.1 & 2295.5 & 3105.7 & 2789.0 & 316.7 & 1806.9 \\
\hline 1985 & 9016.0 & 2541.6 & 3866.6 & 3448.7 & 417.9 & 2607.8 \\
\hline 1986 & 10275.2 & 2763.9 & 4492.7 & 3967.0 & 525.7 & 3018.6 \\
\hline 1987 & 12058.6 & 3204.3 & 5251.6 & 4585.8 & 665.8 & 3602.7 \\
\hline 1988 & 15042.8 & 3831.0 & 6587.2 & 5777.2 & 810.0 & 4624.6 \\
\hline 1989 & 16992.3 & 4228.0 & 7278.0 & 6484.0 & 794.0 & 5486.3 \\
\hline 1990 & 18667.8 & 5017.0 & 7717.4 & 6858.0 & 859.4 & 5933.4 \\
\hline 1991 & 21781.5 & 5288.6 & 9102.2 & 8087.1 & 1015.1 & 7390.7 \\
\hline 1992 & 26923.5 & 5800.0 & 11699.5 & 10284.5 & 1415.0 & 9424.0 \\
\hline 1993 & 35333.9 & 6887.3 & 16454.4 & 14188.0 & 2266.5 & 11992.2 \\
\hline 1994 & 48197.9 & 9471.4 & 22445.4 & 19480.7 & 2964.7 & 16281.1 \\
\hline 1995 & 60793.7 & 12020.0 & 28679.5 & 24950.6 & 3728.8 & 20094.3 \\
\hline 1996 & 71176.6 & 13885.8 & 33835.0 & 29447.6 & 4387.4 & 23455.8 \\
\hline 1997 & 78973.0 & 14264.6 & 37543.0 & 32921.4 & 4621.6 & 27165.4 \\
\hline 1998 & 84402.3 & 14618.0 & 39004.2 & 34018.4 & 4985.8 & 30780.1 \\
\hline 1999 & 89677.1 & 14548.1 & 41033.6 & 35861.5 & 5172.1 & 34095.3 \\
\hline 2000 & 99214.6 & 14716.2 & 45555.9 & 40033.6 & 5522.3 & 38942.5 \\
\hline 2001 & 109655.2 & 15516.2 & 49512.3 & 43580.6 & 5931.7 & 44626.7 \\
\hline 2002 & 120332.7 & 16238.6 & 53896.8 & 47431.3 & 6465.5 & 50197.3 \\
\hline 2003 & 135822.8 & 17068.3 & 62436.3 & 54945.5 & 7490.8 & 56318.1 \\
\hline 2004 & 159878.3 & 20955.8 & 73904.3 & 65210.0 & 8694.3 & 65018.2 \\
\hline 2005 & 183084.8 & 23070.4 & 87046.7 & 76912.9 & 10133.8 & 72967.7 \\
\hline
\end{tabular}

B. Percentage difference in sum provincial pre-economic census values vs. national pre-economic census values

\begin{tabular}{lrrrrrr}
1993 & -1.17 & -0.66 & -0.77 & 0.09 & -6.08 & -2.08 \\
1994 & -2.94 & -1.98 & -3.73 & -2.92 & -8.94 & -2.37 \\
1995 & -1.46 & -0.39 & -5.50 & n.a. & n.a. & 4.24 \\
1996 & 1.03 & 0.69 & -5.03 & -4.04 & -11.43 & 11.24 \\
1997 & 3.35 & 2.87 & -3.11 & -2.63 & -6.31 & 14.08 \\
1998 & 5.66 & 2.17 & -0.08 & -0.09 & -0.02 & 16.48 \\
1999 & 6.83 & 1.04 & 0.49 & -0.02 & 3.79 & 19.43 \\
2000 & 8.65 & 1.48 & 1.89 & 1.12 & 7.01 & 22.33 \\
2001 & 9.71 & 0.84 & 2.27 & 1.09 & 10.15 & 24.79 \\
2002 & 12.22 & 0.61 & 4.88 & 3.51 & 13.90 & 28.18 \\
2003 & 15.46 & 1.47 & 8.39 & 6.94 & 17.81 & 32.56 \\
2004 & 19.26 & 0.62 & 13.89 & 12.77 & 21.29 & 37.00 \\
\hline
\end{tabular}

C. Percentage difference in sum provincial pre-economic census values vs. national post-economic census values

$\begin{array}{rrrrrrr}1993 & -3.13 & -0.74 & -0.92 & -0.22 & -5.32 & -7.54 \\ 1994 & -5.84 & -2.13 & -4.05 & -3.52 & -7.47 & -10.47 \\ 1995 & -5.21 & -0.61 & -5.96 & \text { n.a. } & \text { n.a. } & -6.90 \\ 1996 & -3.64 & 0.39 & -5.66 & -5.23 & -8.54 & -3.12 \\ 1997 & -2.55 & 2.49 & -3.93 & -4.14 & -2.48 & -3.29 \\ 1998 & -1.92 & 1.72 & -1.07 & -1.94 & 4.91 & -4.73\end{array}$




\begin{tabular}{|c|c|c|c|c|c|c|}
\hline 1999 & -2.24 & 0.51 & -0.67 & -2.18 & 9.78 & -5.29 \\
\hline 2000 & -2.02 & 0.87 & 0.50 & -1.38 & 14.10 & -6.06 \\
\hline 2001 & -2.63 & 0.16 & 0.69 & -1.71 & 18.39 & -7.30 \\
\hline 2002 & -1.92 & -0.15 & 3.10 & 0.33 & 23.41 & -7.89 \\
\hline 2003 & -0.21 & 0.63 & 6.37 & 3.33 & 28.67 & -7.76 \\
\hline 2004 & 2.10 & -0.28 & 11.56 & 8.62 & 33.53 & -7.87 \\
\hline \multicolumn{7}{|c|}{$\begin{array}{l}\text { D. Percentage difference in post-economic census national values vs. pre-economic census national } \\
\text { values }\end{array}$} \\
\hline 1978 & 0.58 & 0.00 & 0.00 & 0.00 & 0.00 & 2.45 \\
\hline 1979 & 0.60 & 0.00 & 0.00 & 0.00 & 0.00 & 2.82 \\
\hline 1980 & 0.62 & 0.00 & 0.00 & 0.00 & 0.00 & 2.88 \\
\hline 1981 & 0.60 & 0.00 & 0.00 & 0.00 & 0.00 & 2.75 \\
\hline 1982 & 0.54 & 0.00 & 0.00 & 0.00 & 0.00 & 2.50 \\
\hline 1983 & 0.48 & 0.00 & 0.00 & 0.00 & 0.00 & 2.12 \\
\hline 1984 & 0.52 & 0.00 & 0.00 & 0.00 & 0.00 & 2.10 \\
\hline 1985 & 0.58 & 0.00 & 0.00 & 0.00 & 0.00 & 2.02 \\
\hline 1986 & 0.72 & 0.00 & 0.00 & 0.00 & 0.00 & 2.48 \\
\hline 1987 & 0.80 & 0.00 & 0.00 & 0.00 & 0.00 & 2.74 \\
\hline 1988 & 0.77 & 0.00 & 0.00 & 0.00 & 0.00 & 2.54 \\
\hline 1989 & 0.49 & 0.00 & 0.00 & 0.00 & 0.00 & 1.54 \\
\hline 1990 & 0.65 & 0.00 & 0.00 & 0.00 & 0.00 & 2.06 \\
\hline 1991 & 0.76 & 0.00 & 0.00 & 0.00 & 0.00 & 2.27 \\
\hline 1992 & 1.07 & 0.00 & 0.00 & 0.00 & 0.00 & 3.12 \\
\hline 1993 & 2.02 & 0.08 & 0.16 & 0.31 & -0.80 & 5.90 \\
\hline 1994 & 3.08 & 0.15 & 0.33 & 0.63 & -1.59 & 9.05 \\
\hline 1995 & 3.96 & 0.23 & 0.50 & 0.94 & -2.38 & 11.96 \\
\hline 1996 & 4.85 & 0.30 & 0.66 & 1.26 & -3.16 & 14.82 \\
\hline 1997 & 6.06 & 0.38 & 0.86 & 1.57 & -3.93 & 17.96 \\
\hline 1998 & 7.73 & 0.45 & 1.00 & 1.89 & -4.69 & 22.27 \\
\hline 1999 & 9.27 & 0.53 & 1.17 & 2.21 & -5.46 & 26.10 \\
\hline 2000 & 10.89 & 0.60 & 1.38 & 2.53 & -6.21 & 30.22 \\
\hline 2001 & 12.68 & 0.68 & 1.56 & 2.85 & -6.96 & 34.61 \\
\hline 2002 & 14.41 & 0.75 & 1.73 & 3.17 & -7.70 & 39.15 \\
\hline 2003 & 15.70 & 0.83 & 1.90 & 3.49 & -8.44 & 43.71 \\
\hline 2004 & 16.81 & 0.90 & 2.10 & 3.81 & -9.17 & 48.71 \\
\hline
\end{tabular}

E. Post-economic census: percentage difference in sum provincial vs. national values $2004 \quad 4.82$

$2005 \quad 8.03$

11.35

11.07

13.48

6.71

\# denotes a sub-category.

Pre-economic census national values from the Statistical Yearbook 2005 have typically undergone the single annual revision one year after they were first published; all Statistical Yearbook data quoted in the table incorporate the benchmark revision following the 1993 tertiary sector census. Preeconomic census provincial values of each year are only published once in the Statistical Yearbook series, when they first become available (and thus no revised values are available, although in the early years the provincial data were released a year late, i.e., might incorporate an annual revision). Provincial values would also have been available for 1991 and 1992 (and for provincial GDP only, without subcategories, for 1988-90) from the Statistical Yearbook series, but these are pre-tertiary sector census data; compared to pre-tertiary sector census national data, the sum provincial GDP values are always lower, by up to 4\%. GDP 1952-95 has provincial values for other years, but since the compilation of national income accounts following the System of National Accounts only began in the second half of the 1980s, the comparison of national and sum provincial data would have to be based on retrospectively compiled values.

Sources: Statistical Yearbook 2006, pp. 57, 63f.; pre-economic census national values: Statistical Yearbook 2005, p. 51; pre-economic census provincial values: each year's issue of the Statistical Yearbook. 
Table 2. Original Vs. Revised (Post-Economic Census) Real Growth Rates

\begin{tabular}{|c|c|c|c|c|c|c|c|c|c|}
\hline & \multicolumn{3}{|c|}{ GDP } & \multicolumn{3}{|c|}{ Primary sector } & \multicolumn{3}{|c|}{ Secondary sector } \\
\hline & Orig. & Rev. & Mixed & Orig. & Rev. & Mixed & Orig. & Rev. & Mixed \\
\hline 1993 & 13.5 & 14.0 & 15.9 & 4.7 & 4.7 & 4.8 & 19.9 & 19.9 & 20.0 \\
\hline 1994 & 12.6 & 13.1 & 13.7 & 4.0 & 4.0 & 4.1 & 18.4 & 18.4 & 18.4 \\
\hline 1995 & 10.5 & 10.9 & 11.3 & 5.0 & 5.0 & 5.1 & 13.9 & 13.9 & 14.0 \\
\hline 1996 & 9.6 & 10.0 & 10.3 & 5.1 & 5.1 & 5.2 & 12.1 & 12.1 & 12.2 \\
\hline 1997 & 8.8 & 9.3 & 9.7 & 3.5 & 3.5 & 3.6 & 10.5 & 10.5 & 10.4 \\
\hline 1998 & 7.8 & 7.8 & 9.2 & 3.5 & 3.5 & 3.6 & 8.9 & 8.9 & 9.1 \\
\hline 1999 & 7.1 & 7.6 & 8.4 & 2.8 & 2.8 & 2.9 & 8.1 & 8.1 & 8.2 \\
\hline 2000 & 8.0 & 8.4 & 9.2 & 2.4 & 2.4 & 2.5 & 9.4 & 9.4 & 9.5 \\
\hline 2001 & 7.5 & 8.3 & 9.2 & 2.8 & 2.8 & 2.9 & 8.4 & 8.4 & 8.7 \\
\hline 2002 & 8.3 & 9.1 & 10.0 & 2.9 & 2.9 & 3.0 & 9.8 & 9.8 & 10.1 \\
\hline 2003 & 9.5 & 10.0 & 10.9 & 2.5 & 2.5 & 2.6 & 12.7 & 12.7 & 12.9 \\
\hline \multirow[t]{3}{*}{2004} & 9.5 & 10.1 & 11.0 & 6.3 & 6.3 & 6.4 & 11.1 & 11.1 & 11.3 \\
\hline & \multicolumn{3}{|c|}{ \# Industry } & \multicolumn{3}{|c|}{ \# Construction } & \multicolumn{3}{|c|}{ Tertiary sector } \\
\hline & Orig. & Rev. & Mixed & Orig. & Rev. & Mixed & Orig. & Rev. & Mixed \\
\hline 1993 & 20.1 & 20.1 & 20.5 & 18.0 & 18.0 & 17.0 & 10.7 & 12.1 & 17.2 \\
\hline 1994 & 18.9 & 18.9 & 19.3 & 13.7 & 13.7 & 12.8 & 9.6 & 11.0 & 12.9 \\
\hline 1995 & 14.0 & 14.0 & 14.4 & 12.4 & 12.4 & 11.5 & 8.4 & 9.8 & 11.3 \\
\hline 1996 & 12.5 & 12.5 & 12.8 & 8.5 & 8.5 & 7.6 & 7.9 & 9.4 & 10.7 \\
\hline 1997 & 11.3 & 11.3 & 11.6 & 2.6 & 2.6 & 1.8 & 9.1 & 10.7 & 12.1 \\
\hline 1998 & 8.9 & 8.9 & 9.2 & 9.0 & 9.0 & 8.1 & 8.3 & 8.3 & 12.3 \\
\hline 1999 & 8.5 & 8.5 & 8.8 & 4.3 & 4.3 & 3.4 & 7.7 & 9.3 & 11.1 \\
\hline 2000 & 9.8 & 9.8 & 10.1 & 5.7 & 5.7 & 4.9 & 8.1 & 9.7 & 11.6 \\
\hline 2001 & 8.7 & 8.7 & 9.0 & 6.8 & 6.8 & 6.0 & 8.4 & 10.2 & 12.1 \\
\hline 2002 & 10.0 & 10.0 & 10.3 & 8.8 & 8.8 & 7.9 & 8.7 & 10.4 & 12.4 \\
\hline 2003 & 12.8 & 12.8 & 13.2 & 12.1 & 12.1 & 11.2 & 7.8 & 9.5 & 11.3 \\
\hline 2004 & 11.5 & 11.5 & 11.8 & 8.1 & 8.1 & 7.2 & 8.3 & 10.0 & 12.1 \\
\hline
\end{tabular}

\# denotes a sub-category

Orig.: original, pre-economic census real growth rates as published in the Statistical Yearbook 2005.

Rev.: revised real growth rates following the 2004 economic census.

Mixed: revised nominal values from 2004 economic census combined with implicit deflators from Statistical Yearbook 2005; secondary sector real growth rates are aggregates of industry and construction real growth rates (using a Törnqvist index, with post-economic census nominal values as weights); real GDP growth rates are compiled from those of the three main economic sectors.

Sources: Statistical Yearbook 2005, pp. 51, 53; 2006, pp. 57, 59. 
Table 3. Ratio of Post- to Pre-Economic Census Expenditure Approach Value Added

\begin{tabular}{|c|c|c|c|c|c|c|c|c|c|c|}
\hline & \multirow[t]{3}{*}{ GDP } & \multicolumn{5}{|c|}{--- --- --- Final consumption --- --- --- } & \multicolumn{3}{|c|}{ Gross capital formation } & \multirow{3}{*}{$\begin{array}{c}\text { Net } \\
\text { exports }\end{array}$} \\
\hline & & \multirow[t]{2}{*}{ Total } & \multicolumn{3}{|c|}{ Household } & \multirow[t]{2}{*}{ Gov. } & \multirow[t]{2}{*}{ Total } & \multirow[t]{2}{*}{ Fixed } & \multirow{2}{*}{$\begin{array}{l}\text { Change in } \\
\text { inventories }\end{array}$} & \\
\hline & & & Total & Rural & Urban & & & & & \\
\hline 1978 & 1.000 & 1.000 & 1.000 & 1.000 & 1.000 & 1.000 & 1.000 & 1.000 & 1.000 & 1.000 \\
\hline 1979 & 1.005 & 1.005 & 1.003 & 0.995 & 1.017 & 1.013 & 1.003 & 1.002 & 1.009 & 1.020 \\
\hline 1980 & 1.009 & 1.011 & 1.006 & 0.989 & 1.034 & 1.027 & 1.006 & 1.003 & 1.019 & 0.993 \\
\hline 1981 & 1.022 & 1.016 & 1.009 & 0.983 & 1.052 & 1.041 & 1.031 & 1.069 & 0.887 & 1.513 \\
\hline 1982 & 1.018 & 1.021 & 1.012 & 0.979 & 1.071 & 1.054 & 1.014 & 1.007 & 1.052 & 0.999 \\
\hline 1983 & 1.023 & 1.026 & 1.015 & 0.974 & 1.091 & 1.068 & 1.017 & 1.008 & 1.067 & 1.000 \\
\hline 1984 & 1.028 & 1.032 & 1.018 & 0.969 & 1.109 & 1.083 & 1.019 & 1.010 & 1.073 & 1.000 \\
\hline 1985 & 1.032 & 1.037 & 1.021 & 0.962 & 1.126 & 1.097 & 1.021 & 1.012 & 1.054 & 1.001 \\
\hline 1986 & 1.037 & 1.043 & 1.025 & 0.953 & 1.141 & 1.112 & 1.025 & 1.013 & 1.072 & 1.000 \\
\hline 1987 & 1.042 & 1.047 & 1.028 & 0.945 & 1.157 & 1.127 & 1.032 & 1.015 & 1.144 & 0.939 \\
\hline 1988 & 1.047 & 1.051 & 1.031 & 0.933 & 1.169 & 1.142 & 1.037 & 1.017 & 1.146 & 1.000 \\
\hline 1989 & 1.051 & 1.058 & 1.034 & 0.924 & 1.184 & 1.157 & 1.039 & 1.019 & 1.090 & 1.001 \\
\hline 1990 & 1.056 & 1.064 & 1.037 & 0.913 & 1.197 & 1.172 & 1.047 & 1.020 & 1.121 & 1.000 \\
\hline 1991 & 1.061 & 1.072 & 1.040 & 0.901 & 1.208 & 1.188 & 1.047 & 1.022 & 1.140 & 1.000 \\
\hline 1992 & 1.066 & 1.078 & 1.043 & 0.888 & 1.217 & 1.204 & 1.047 & 1.024 & 1.192 & 1.000 \\
\hline 1993 & 1.071 & 1.085 & 1.047 & 0.872 & 1.223 & 1.220 & 1.048 & 1.025 & 1.194 & 1.000 \\
\hline 1994 & 1.076 & 1.091 & 1.050 & 0.861 & 1.235 & 1.236 & 1.056 & 1.027 & 1.260 & 1.000 \\
\hline 1995 & 1.080 & 1.093 & 1.053 & 0.851 & 1.248 & 1.252 & 1.067 & 1.029 & 1.282 & 1.000 \\
\hline 1996 & 1.085 & 1.098 & 1.056 & 0.848 & 1.273 & 1.269 & 1.071 & 1.031 & 1.341 & 1.000 \\
\hline 1997 & 1.090 & 1.105 & 1.059 & 0.836 & 1.283 & 1.286 & 1.053 & 1.032 & 1.212 & 1.242 \\
\hline 1998 & 1.095 & 1.112 & 1.063 & 0.819 & 1.286 & 1.303 & 1.060 & 1.034 & 1.433 & 1.189 \\
\hline 1999 & 1.100 & 1.119 & 1.066 & 0.804 & 1.290 & 1.320 & 1.073 & 1.036 & 1.977 & 1.056 \\
\hline 2000 & 1.105 & 1.127 & 1.069 & 0.789 & 1.296 & 1.338 & 1.072 & 1.037 & n.a. & 1.067 \\
\hline 2001 & 1.105 & 1.135 & 1.072 & 0.778 & 1.306 & 1.356 & 1.062 & 1.026 & 3.112 & 1.054 \\
\hline 2002 & 1.115 & 1.142 & 1.075 & 0.765 & 1.314 & 1.374 & 1.077 & 1.041 & 5.000 & 1.107 \\
\hline 2003 & 1.120 & 1.148 & 1.079 & 0.747 & 1.313 & 1.392 & 1.086 & 1.043 & 9.858 & 1.113 \\
\hline 2004 & 1.126 & 1.154 & 1.082 & 0.734 & 1.319 & 1.411 & 1.100 & 1.044 & 7.732 & 1.000 \\
\hline
\end{tabular}

The year 2000 value of the change in inventories is $-12.4 \mathrm{~b}$ yuan RMB in the pre-economic census series, and 99.84b yuan RMB in the post-economic census series.

Sources: Statistical Yearbook 2005, pp. 63f., 2006, pp. 68f. 


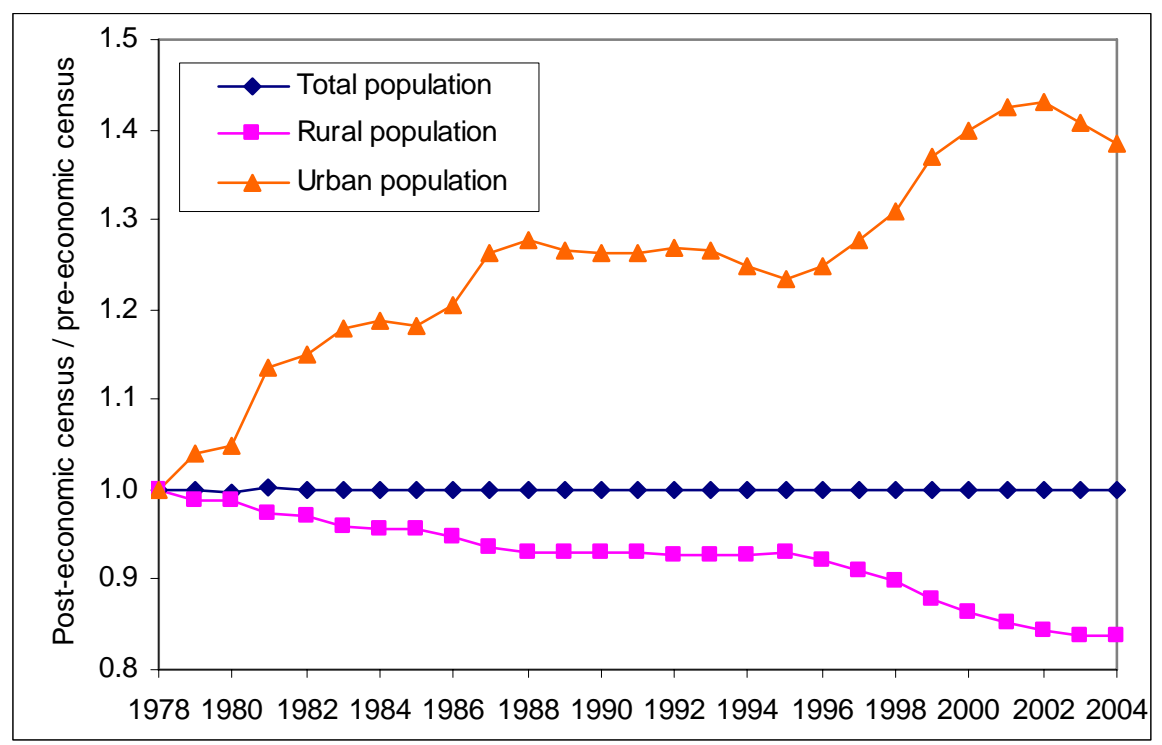

Sources: for aggregate (nominal) values see sources to Table 3; per capita (nominal) values:

Statistical Yearbook 2006, p. 73; 2005, p. 68; 2003, p. 72; 2001, p. 66.

Figure 1. Post- Vs. Pre-Economic Population Numbers Implicit in Aggregate and Per Capita Household Consumption Values

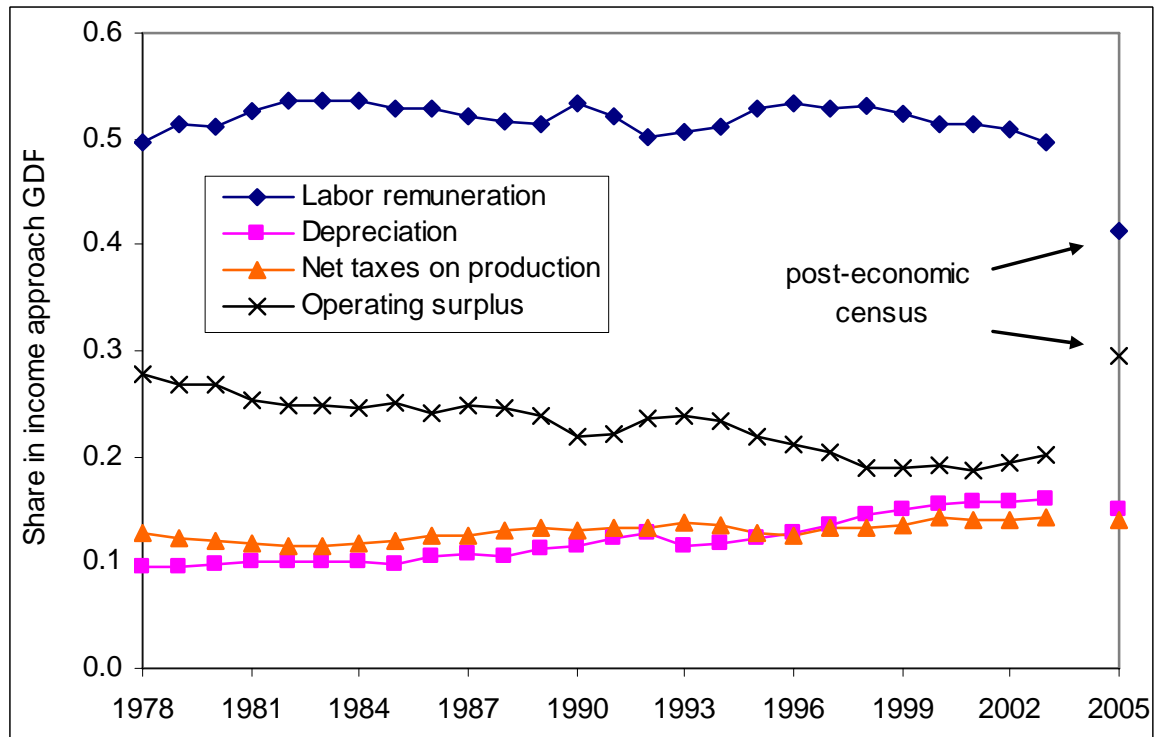

All data are sum provincial (nominal) data. National values have not been released.

1978-2003 are pre-economic census values; these have not been revised. 2004 values are not available. The 2005 values are post-economic census values.

Sources: 1978-1995: GDP 1952-95; 1996-2005: individual issues of the Statistical Yearbook 1997 through 2006.

Figure 2. Shares of Individual Components in Income Approach GDP 